\title{
Strategy Research on Health Tourism of Traditional Chinese Medicine
}

\author{
Zehui Jiang ${ }^{1}$, Jun Zhang ${ }^{2}$ \\ ${ }^{1}$ Jiangxi University of Traditional Chinese Medicine, Nanchang, Jiangxi, China; \\ ${ }^{2}$ Department of Cardiovascular Medicine, the 94th Hospital of Chinese People's Liberation Army, Nanchang, \\ Jiangxi, China \\ Communication Author: Jun Zhang
}

Keywords: Traditional Chinese medicine; health tourism; Strategy Research

\begin{abstract}
This paper summarizes the concept and form of traditional Chinese medicine tourism, analyzes the current development of Chinese medicine health tourism and the existing problems, and puts forward some countermeasures and suggestions on comprehensive development of Chinese medicine health tourism.

Traditional Chinese medicine health tourism is a relatively rapid development of medical tourism in recent years. Traditional Chinese medicine health tourism is the integration of traditional Chinese medicine culture and tourism, so that people feel the Chinese medicine culture in the process of tourism to their health enjoyment, to better meet people's growing health tourism demand.
\end{abstract}

\section{The connotation of health tourism of traditional Chinese Medicine}

The health tourism of traditional Chinese medicine is an ecotourism project based on rich Chinese medicinal material resources and deep traditional Chinese medicine culture. It is an organic integration of traditional Chinese medicine culture, Chinese medicine industry, tourism industry and cultural creative industry. It is a new form of creative tourism and its industrial chain with the theme of providing traditional Chinese medicine, cultural transmission, health care, medical rehabilitation and other services. The health tourism of traditional Chinese medicine has the characteristics of strong regionalism, unique medical and health care of traditional Chinese medicine and the profound connotation of traditional culture.

\section{Problems existing in traditional Chinese medicine health tourism}

The form of health tourism products of traditional Chinese medicine is mainly based on ornamental and medicinal materials, health care, but the scale is small and the level is low. There is still a big gap in hardware facilities and service capabilities. Chinese medicine health tourism industry internal factors fragmented, failed to form a resultant force. Such as the health tourism of traditional Chinese medicine, there are heavy sightseeing, merchandising, light Chinese medicine culture and the experience of health care means of traditional Chinese medicine.

The Chinese government has attached great importance to the development of Chinese medicine health tourism industry, are also aware of the health of Chinese medicine tourism has broad market prospects. But in most parts of China, there is no systematic investigation report on the development of TCM health tourism, nor a unified and clear thinking about the development of traditional Chinese medicine tourism resources, and large-scale tourism enterprises participation is not high in traditional Chinese medicine health tourism.

Chinese medicine health tourism is still in lack of system integration. It has not formed the industrial chain and scale industrial cluster economy. Chinese medicine health tourism have many problems, such as the characteristics of traditional Chinese medicine culture is not prominent, the regional structure of the problem, the lack of innovation, industrial facilities are not in place etc.

Chinese medicine health tourism industry is an emerging industry. Due to the particularity of 
Chinese medicine, Chinese medicine health professionals in the tourism industry is serious shortage. The theoretical research on health tourism industry of Chinese medicine colleges is relatively weak, and the system and mode of training high-end professionals are still at the embryonic stage. The training of traditional Chinese medicine health service talents based on secondary and tertiary schools also has the drawbacks of similar training mode, lack of distinctive academic characteristics and lack of theoretical innovation. The lack of talents is bound to affect the promotion and construction of all sectors of the industry, hindering the large-scale development of traditional Chinese medicine health tourism industry.

\section{Countermeasures and suggestions}

We should strengthen the integration and linkage of Chinese medicine, natural tourism and health related industries in different regions, and build scale and brand effect through technological development, service innovation and market creation, thus forming a healthy tourism industry cluster chain of Chinese medicine. The area to comply with the local situation, taking economic construction as the center, facing the market, according to the unique traditional tourism resources and profound Chinese medicine Torben regional cultural foundation and other special resources, break the portal prejudice, win-win cooperation, establish a comprehensive, diversified, multi-level Chinese medicine health tourism service brand exploration.

The government should plan the development of the health tourism of traditional Chinese medicine in detail, and strengthen the macro control and policy support in the relevant departments. The area will be in the macro guidance of the party and the country, according to the basic situation of the country, measures and specific application of formulation of the corresponding basic requirements, earnestly implement the preferential policies of Chinese medicine and health services, the courage to play and promote the traditional Chinese medicine culture, promote the rapid development of medical tourism industry.

Information society has put forward higher requirements for the marketing service of traditional Chinese medicine health tourism industry. Therefore, we should enhance the cross penetration and integration of traditional Chinese medicine health tourism industry and cultural consumption, Internet and other industries, and strengthen professional training. At the same time, we should promote the combination of traditional Chinese medicine health tourism industry service concept and product marketing, and build distinctive brand based on regional advantages, so that traditional Chinese medicine culture will become an important factor in the development of traditional Chinese medicine healthy tourism industry.

To encourage and support Chinese medicine colleges and universities occupation closely around the needs of health tourism of Chinese medicine, to further clarify the running pattern of positioning and professional development, actively cultivate applied talents and skills of Chinese medicine talents, composite talents and high-level innovative talents of different levels of talent, and to ensure the demand as the focus, scientific layout of Chinese medicine health tourism occupation training education.

\section{References}

[1] Wang Jingming, Wang Jing and. Thought and exploration of the development of traditional Chinese medicine tourism [J]. Explore the economic issues, 2000 (8): 85 - 86.

[2] Zhang Chunli. Hangzhou health care tourism development analysis of traditional Chinese medicine [J]. Chinese national folk medicine, 2009 (11): 3638.

[3] Shi Shuai. The present situation of Chinese medicine tourism in China [J]. Chinese medicine information magazine, 2014, 21 (1): 5 - 6.

[4] The cloud, Lixin, Wang Zhihong, et al. Traditional Chinese medicine of Gansu Province cultural tourism industry development strategy research of J Chinese. Journal of medicine, 2016, 23 (2): 11 14. 
[5] Hou Zheng. Yu Zheng. SWOT of Chinese medicine tourism in China Analysis [J]. Health economics research, 2013 (2): 19 - 22.

[6] Sun Xiaosheng, Li Liang. Guangdong traditional Chinese medicine culture health preservation tourism development present situation and countermeasure research [J]. Chinese medicine management magazine, 2013, 21 (5): 42-444. 